Studia Slavica Savariensia 2016. 1-2. 186-193

DOI: $10.17668 /$ SSS.2016.1-2.186

Жанна Игнац

(Сомбатхей, Венгрия)

\title{
ФОЛЬКЛОРНЫЕ ТРАДИЦИИ В ТВОРЧЕСТВЕ ВЛАДИМИРА ВЫСОЦКОГО
}

\begin{abstract}
To represent contemporary reality, the poet and singer Vladimir Vysotsky uses in his works traditional folk stories, genres, motifs and images, evoking this way in the audience brought up on the folk traditions association with folklore, which is one of the reasons for the popularity of Vladimir Vysotsky's works among all social and cultural sectors of society.

Keywords: Vysotsky, folklore, thieves songs, fairy tales, demythologization, irony

Владимир Семенович Высоцкий - советский актер театра и кино, поэт и исполнитель своих произведений в жанре авторской песни был чрезвычайно популярен во всех социально-культурных слоях общества.

Секрет его феноменальной популярности состоял и в том, что его творчество основывалось на традициях мировой и русской классической литературы, а также мирового и русского фольклора. Его произведения отличаются фольклоризмом, то есть автор в разработке своей литературной темы использует присущие фольклору приемы, язык, интонации, стилистику, образы и мотивы. Высоцкий не писал «авторские» народные песни или сказки, он лишь использовал фольклорные традиции в современной - в его случае урбанизированной трансформации фольклора, вызывая у своего слушателя ассоциацию с усвоенными из поколения в поколение образцами народного творчества.

Высоцкий обращался к таким жанрам народного творчества, как сказка («Сказка о несчастных сказочных персонажах», и др.), песня («Песня Марьи», и др.), частушка («Видно, острая заноза в душу врезалась ему...» и др.), басня («Дурачина-простофиля» и др.), пословища («Разбойничья песня»), былина («Песня Соловья-Разбойника и его дружков»), баллада («Баллада о времени», и пр. из цикла баллад к фильму «Стрелы Робин Гуда»), романс («Городской романс).

Начинал Высоцкий с «нетрадиционного фольклора», с так называемых «блатных песен», основанных на традициях жанра городской, мещанской субкультуры «жестокого» и «городского» романса с ярко выраженной уголовной и бытовой тематикой (СКОБЕЛЕВ 1990: 64).
\end{abstract}


Первые блатные песни Высоцкого это стилизация (СКОБЕЛЕВ, ШАУЛОВ 2001) ${ }^{1}$ под блатной фольклор, с ярко выраженным «ролевым героем». Позже, по ходу творческой и личной эволюции, произошла трансформация обращения с блатным материалом в лирическую сторону: исчезли стилизация, характерный блатной сюжет, иронично-пародийный стиль. В обыгрывающей библейский сюжет похищения райских яблок песне «Райские яблоки», блатные мотивы (этап, «малина») пересекаются с мифологическими (райские сады, яблоки, ворота, апостол Петр, распятый Христос), и сказочными (гиблое место, конь), а блатной мир перемещен уже в трансцендентальную плоскость. Герой, выбирая между тем и этим миром, в конечном счете, возвращается назад, в мир этот, потому что там - «неродящий пустырь», «беспредел», и яблоки-то, мороженные, а тут, дома, ждут даже из Рая.

Сказочный мотив возвращения (путешествие героя волшебной сказки в потусторонний мир и обратно (ПРОПП 2000: 32) встречается у Высоцкого очень часто. Но у него оппозиция «здесь - там» осложнена. Если герой волшебной сказки вернувшись с потустороннего мира «сюда», выполнив задание и получив заслуженную награду больше уже никуда не стремится, да и не может, потому что сказка на этом заканчивается, то вернувшихся «сюда» героев Высоцкого манит назад, «mуда», награда ждет их «там»: корабли («Корабли постоят и ложатся на курс...») и альпинисты («Прощание с горами») возвращаются «сюда» только потому, что «.../ просто некуда деться», а после снова стремятся вернуться «myдa».

Помимо блатных мотивов в творчестве Высоцкого появляются и фольклорные, которые он использовал в собственном, авторском переосмыслении, в поэтической обработке.

Одним из основных проявлений у Высоцкого авторского подхода, в том числе, и к фольклорному материалу было использование приемов снижения, травестии и пародии жанров, образов и сюжетов, что в принципе соответствовало как русским народным традициям пародии «высоких» фольклорных жанров - былин, сказок, свадебных песен (НОВИКОВ 2002: 74), так и традициям советской литературы (КУЛАГИН 2013: 99).

Но Высоцкий не просто снижает, он демифологизирует традиционные фольклорные персонажи и сюжеты. Сказки у него становятся «антисказками», как песня «Лукоморья больше нет. Антисказка». Если реальность времен Пушкина позволяла создавать сказку, то реальность времен Высоцкого побеждает сказочный мир Пушкина, причем данный факт заявлен в самом начале, открытым текстом: «Лукоморья больше

\footnotetext{
${ }^{1}$ Сам Высоцкий называл их «пародиями на блатные песни», а по мнению Л.В. Абрамовой (2-й жены Высоцкого) это были просто блатные песни без всякой стилизации (КУЛАГИН 2013: 9)
} 
нет...», и далее: дуб - порублен на гробы, кот - отнес золотую цепь в Торгсин, Черномор - первый вор, русалка - родила, а «Тридцать три же мужика не желают знать сынка» и т.д., констатируя в конце, что «Все, о чем писал поэт, - это бред.». Как двояко в таком контексте воспринимаются слова из «Марша авиаторов» (Хайт Ю.А., Герман П.Д., 1923): «Мы рождены, чтоб сказку сделать былью, /.../».

На сюжетном уровне происходит или авторская переработка традиционного фольклорного сюжета: например при участии традиционных сказочных персонажей развивается привычный для волшебной сказки сюжет - возникла беда, последовал призыв о помощи, обещана награда, найден герой. Но после нескольких ходов сюжет сказки ломается: герой - «бывший лучший, но опальный стрелок» («Про дикого вепря») - сперва отказывается от награды в лице принцессы в пользу бадьи портвейна, а после того, как антагонист побежден сваливает с бадьей, то есть опять «антисказка».

Или посредством ввода пары фольклорных элементов создается лишь ассоциация со сказкой, а сказочные реалии используются для изображения действительности.

Зачастую на фольклорный лад настраивал уже само название: «Сказка о несчастных сказочных персонажах», «Странная сказка» и пр..; или зачин песни: «Жил-был...», но после ничего сказочного не происходило, а сразу следовал «откат» в реальность: жил-был «один чудак», оказавшийся невыездным и писавший по этому поводу заказные письма («Жил-был один чудак...»); «Как во городе во главном // Как известно - златоглавом // В белокаменных nалатах //.....// Собралися на банкет /.../» («Как во городе во главном...»). Но, несмотря на это требуемый эмоциональный настрой был уже обеспечен, а нарушение ожидания сказки вызывало комический эффект.

Высоцкий использует много пословиц и постоянных эпитетов фольклорного типа, за счет чего достигается эффект разговорности, передается авторская позиция или склад мыслей персонажа или лирического героя (КУЛАГИН 2013: 76). Пословицы используются как в неизмененном виде: «А где тонко - там и рвется» («Песня о двух красивых автомобилях), «Молодо - зелено!» («Марш физиков»), так и в измененном, или обыгранном виде: «Но под властью татар жил Иван Калита, // И уж был не один, кто один против ста» («Мне судьба - до последней черты, до креста») вместо: «Один в поле не воин» (ДАЛЬ 1862); «Все скоро обуздается, // И встанет на места //» («Жил был один чудак...») вместо: «Все перемелется, мука будет» (ДАЛЬ 1862). В «Разбойничьей песне» Высоцкого вместо «Сколь веревку не вить, а концу быть» (ДАЛЬ 1862) встречаем: «Сколь веревочка не вейся, все равно совьешься в кнут! /.../ в плеть! /.../ в петлю!». Высоцкий несколько раз меняет слова пословицы на синонимы одного тематического ряда, добиваясь большего эмоционального эффекта (ЕВТЮГИНА 2000: 10). 
Иногда пословица является сюжетообразующим элементом, как в «Песенке про Козла отпущения», обыгрывающей пословицу «С волками жить - по волчьи выть». Здесь в развязке позиция автора совпадает с пословничной мудростью, но иногда он спорит с ней, как в «Моей цыганской», где оспаривается утверждение о том, что «Утро вечера мудренее», у него: «Но и утром всё не так, /../». То есть автор ведет диалог с фольклором, то соглашаясь, то споря с ним.

Для Высоцкого характерно сочетание разговорного и литературного слова, разбавление определенной литературной формы. Так и фольклорные эпитеты применяются им в сочетании с характерным для него разговорным, сниженным, а то и с жаргонным словом: «ханыга», «прощелыга», «забулдыга» и «сквалыга» собрались на дармовой госбанкет в «белокаменных палатах», где «три богатыря» стоят на дежурстве, «жар-пртица» - жареная, а «скатерть-самобранка» от слова «бранить» («Как во городе во главном...»); в «держсве» - лозунги, митинги, пикеты и брандспойт («В одной державе с населеньем...»). Слово Высоцкого обычно разговорное, сниженное, далекое от «высокого стиля», фольклорное слово придает ему необходимую поэтичность и драматизм (КОПЫЛОВА 1990: 78).

Фольклорные выражения и фразеологизмы применяются им в измененном: «дремучий лес» вместо «дикий лес» («Песня-сказка о нечисти»), или обыгранном виде: «Сказали: «Звёзды с неба - не хватать!» («Реальней сновидения и бреда») вместо «звезд с неба не хватает», что позволяет избегать стилизации и соблюдать дистанцию между поэтическими системами фольклора и самого автора (КОПЫЛОВА 1990: 78).

Встречаются метафорические ассоциации со сказкой: «Наше время иное, лихое, // но счастье, как встарь, ищи!» («Песня о новом времени»); ассоциации с народными песнями: «Черный Ворон, что ты вьешься //» («Видно, острая заноза в душу врезалась ему...»), «Эй, ухнем! // Эй, охнем! // Пусть рухнем - // Зато просохнем!» («Странные скачки) и пр. - все это популярные и широко известные в широких кругах произведения. Встречаются и ассоциации с поверьями: «То черный кот, то кто-то в чемто черном,/» («Горизонт»). Здесь «кто-то в чем-то чером» может быть измененным эпитетом и ассоциироваться с облаченным в черную одежду предвестником беды (КОПЫЛОВА 1990: 75), но, в сочетании с «napu», условия которого «одобрили не все» и с общей тематикой стихотворения может ассоциироваться и с Пушкиным на биографическом уровне. Ассоциации с основанными на суевериях - в данном случае недобрыми поверьями, которые, пожалуй, являются наиболее узнаваемым фольклорным элементом, придают тексту драматичность и особый подтекст. 
Фольклорные образы Высоцкого по составу идентичны своим фольклорным прототипам, но представлены, опять же, в измененном виде, в авторской переработке.

В авторской интерпретации Высоцкого традиционные фольклорные персонажи - Соловей-Разбойник, Леший, Баба-Яга, Кащей Бессмертный, Змей-Горыныч, Кикимора, и пр. - могут обрести положительный характер и отличные от фольклорных прототипов личные качества, что в некоторых случаях добавило им симпатии и за счет чего они утратили свою устрашающую функцию и перестали быть носителями зла. Влюбленный Соловей-разбойник в «Серенаде Соловья-разбойника» «свищет» серенаду любимой Аграфене, по-купечески набиваясь к ней в женихи. Персонажи эти персонифицированы на новый лад, «осовременены»: Джинн («Песня-сказка про Джинна») вместо лампы живет в бутылке вина, которую тереть три раза уже не надо, достаточно просто вынуть пробку, он явно «подшофе» - противный, пахучий и с видом грубого мужика. Царские особы становятся «демократичнее»: свой в доску царь «Стрельнет, коль надо, папироску, -/.../ («В одной державе с населеньем»).

Персонажи, попавшие в городские условия, начиная жить по людским законам утрачивают свой сказочный облик и становятся похожими на людей в плохом смысле этого слова: в песне «От скучных шабашей смертельно уставши», нечисть решает переселиться в город, где: «Освоились быстро, - // Под видом туристов // Поели-попили в кафе «Гранд-отель». Затем прихорошились: вурдалак «спрятал клыки» и стал «красавчиком», а леший побрился. В конечном счете им не удалось избежать пагубного влияния города и закончилось все тем, что «/.../ ведьмы выли // И все просадили, /.../ леший пил-надирался в кафе, -/.../», а Вурдалак, который до поездки в город пообещал вести себя хорошо «Найдя себе вдовушку, / Выпив ей кровушку, / Спал /..../ на софе.», то есть «сколько волка ни корми, он все-равно в лес смотрит». В экстремальных для себя условиях персонажи становятся несчастными. В «Сказке о несчастных сказочных персонажах» несчастны все: Змей Горыныч «/.../ грубое животное /.../ Но по-своему несчастное и кроткое», Кащей «От любви к царице высох и увял - / И стал по-своему несчастным старикашкою.», «/.../ по-своему несчастен был...» и Иван-дурак и посвоему несчастная «бедная узница», и вся «лесная голытьба».

Но преображается и реальный мир, если он оказывается в сказке: в «Сказку о несчастных сказочных персонажах» попадает прекрасное («/.../ сверкает, как зарница») и «ужасное» здание ООН, которое вместо поддержания мира во всем мире становится местом заточения царицы, которая, соответственно, попав в город (Нью-Йорк) несчастна вместе с остальными несчастными персонажами этой сказки.

Нарушаются привычные судьбы и функции сказочных персонажей: Кащей умирает «/../ сам /.../ без всякого вмешательства» («Сказка о 
несчастных сказочных персонажах»); Водяной по привычке потянулся за утопленником, а тот его «- пятой по рылу!../», - что ни говори, «/.../ перестали совсем уважать / Нашу нечистую силу!» («Куплеты нечистой силы»).

Традиционно имеющиеся в одном числе фольклорные персонажи «тиражируются»: встречаются соловьи-разбойники («Песня-сказка о нечисти»), Сивка и Бурка («Укатали Сивку»), Бабы-Яги («Сказка о несчастных лесных жителях»), «А изб на ножках - здесь не видели таких» («Бывало, Пушкина читал всю ночь до зорь я...»).

Часто используются персонажи и мотивы из разных фольклорных систем. В песне «Про дикого вепря» рядом с традиционно русскими «Чудо-юдом» встречаем не характерных для русского фольклора «королевство», «короля», «принцессу» и «тура». Самого победившего Чудо-юдо стрелка на первый взгляд можно было бы принять за русского «стрельца», но охарактеризованный, как «бывший лучший королевский стрелок» и в сочетании с «бадьей портвейна» ассоциируется скорее с разбойниками из Шервудского леса. Все эти приемы «особого» обращения с персонажами создают комический, иронический эффект.

Широко использовались Высоцким сказочные мотивы: мотив коня средства перемещения героя в пространстве («Кони привередливые», «Райские яблоки»), бани - места очищения, места на краю леса на границе между тем и этим миром («Банька по-белому», «Банька почерному»). В песне «Инструкция перед поездкой зарубеж» герой социалистического труда кузнец («Я вчера закончил ковку, и два плана залудил») получает задание («И в загранкомандировку от завода угодил»), очищается в бане («Копоть, сажу смыл под душем»), принимает пищу («Съел холодного язя, /.../») $)^{2}$, получает запреm («И инструктора послушал - что там можно, что нельзя») и при помощи помощников (жены «/.../ провожала /.../ отутюжила рубашки» и собутыльников «Пили мы /.../») улетает на волшебном средстве, (ковре)самолете («Я весь путь к аэропорту проикал») в потусторонний мир (в заграницу) перед тем во сне пережив сражения с различными антогонистами («венгерки с бородами и ружьем», «немецкие румынки» из «польского города Будапешт») посягающими на его моральный облик ("Там шпионки с крепким телом, / Ты их в дверь - они в окно»).

Пользуется Высоцкий и присущим фольклору приемом иносказания. В песне «Дурачина-простофиля» адаптирован сюжет пушкинской «Сказки о рыбаке и рыбке»: роль золотой рыбки выполнет здесь «стул для царских кровей» на который уселся «ответственный мужчина», которым овладела мания величия и он начал «/.../ топать /.../ ногами и кричати». В дурчине-

\footnotetext{
${ }^{2}$ В волшебной сказке банька и трапеза обязательный ритуал перед разговором с бабой-ягой (ПРОПП 2000: 49), которая в данной песне персонифицирована в лице инструктора, находящийся на границе «того» и «этого» мира.
} 
простофиле хорошо угадывается Н.Хрущев, прославившийся своими недипломатическими манерами и издавший «указ про изобилие» - на XXII съезде КПСС обозначил сроки построения коммунизма. Общее между двумя героями - их преувеличенные запросы на фоне низкого социального происхождения, что, в конечном счете, надоедает и золотой рыбке и «стулу для царских кровей», и оба персонажа остаются у разбитого корыта.

Знаком Высоцкому и прием гиперболизации: «Словно пробудилися // молодиы былинные // И, числом несметные, // встали из земли.» («Песня о Волге»), «Берега над ней - сплошь кисельные - /», применяемый им даже и на сюжетном уровне как в песне «Две судьбы», в которой у героя сразу две судьбы - Кривая и Нелегкая.

Как показал анализ, В.Высоцкий широко использует фольклорные традиции в своем творчестве, что, разумеется, далеко не единично в своем роде. Разница в подходе и в методе освоения темы.

Высоцкий не пишет что-то стилизированное под народное творчество, соблюдая законы жанров, он внедряет фольклорный материал используя фольклорные сюжеты, жанры, мотивы и образы в авторской обработке для изображения современной действительности, сохраняя при этом дистанцию между собственной и фольклорной темой. Дистанция выдерживается за счет деавтомаизации жанров, демифологизации образов, трансформации сюжетов и ситуаций, что придает тексту комический, иронический эффект, при возможности усиливаемый и стилистикой авторского исполнения.

Приемы разработки литературной темы отражают мировоззрение автора, предопределяют его аудиторию. Высоцкий использует массово известные элементы фольклора вымеренно, но в достаточном количестве для того, чтобы обеспечить узнаваемость фольклорного слова и вызывать фольклорные ассоциации у своей аудитории. Такой прием освоения фольклорных и литературных традиций совпадает с запросами его аудитории, его слушатель/читатель - воспитанный на русском и мировом фольклоре - открыт для восприятия хранимых в коллективной бессознательной памяти смыслов и подтекстов.

\section{Литература}

ДАЛЬ 1862 = ДАЛЬ В.И. «Пословицы русского народа». Москва, 1862. http://dlib.rsl.ru/viewer/01003565716\#?page $=1$

ЕВСТЮГИНА 1995 = ЕВСТЮГИНА А.А. «Читайте простонародные сказки» // Альманах «Мир Высоцкого» вып. 2, 1995. 244-257. http://vv.mediaplanet.ru/links КУЛАГИН 2013 = КУЛАГИН А.В. «Поэзия В.С. Высоцкого. Творческая эволюция». (Издание третье, переработанное), Воронеж, 2013. http://litved.com/docs/Kulagin-Poezia-Vusotskogo.pdf 
КОПЫЛОВА 1990 = КОПЫЛОВА Н.И «Фольклорная ассоциация в поэзии В.С. Высоцкого» // «В.С. Высоцкий: Исследования и материалы», Воронеж, 1990. 74-95.

НОВИКОВ 2002 = НОВИКОВ В.И. «Высоцкий» // «Жизнь замечательных людей», вып. $829 . \quad$ Москва: «Молодая гвардия», 2002. http://royallib.com/read/novikov_vladimir/visotskiy.html\#0

ПРОПП 2000 = ПРОПП В.Я. «Исторические корни волшебной сказки» (1946). Москва: «Лабиринт», 2000.

СКОБЕЛЕВ 1990 = СКОБЕЛЕВ А.В. Фольклорная традиция в поэзии Владимира Высоцкого («блатные» песни: темы и образы) // Folklorrezeption in der Gegenwart. Probleme des Folklorismus in den slawischen und baltischen Literaturen. Rostocker Forschungen zur Sprach- und Literaturwissenschaft. Heft 8. 1990. S. 6468. http://vv.mediaplanet.ru/links

СКОБЕЛЕВ, ШАУЛОВ 2001 = СКОБЕЛЕВ А.В., ШАУЛОВ С.М. «Владимир Высоцкий: Мир и слово». (Второе издание) Уфа, 2001. http://vv.mediaplanet.ru/books/Skobelev_SHaulov-Mir_i_slovo 